\title{
Scientific Management Theory and Human Depreciation
}

\author{
Mohammad Kabirnejat ${ }^{1}$ and Sirous Tabrizi ${ }^{2}$ \\ ${ }^{1}$ Islamic Azad University of Hashtrood, Iran \\ ${ }^{2}$ University of Windsor, Windsor, Canada
}

\begin{abstract}
Globalization and its policies have a direct effect on developing countries, from increased productivity to pollution and larger gap between the rich and poor. Of the four major management approaches to organizational theory, some companies prefer to use the classical approach introduced by Frederick Taylor. This approach maximizes prosperity for owners, workers, and managers in the industry by teaching workers and managers the most efficient way to do their work. However, antagonism and inefficiency in the workplace occurred, caused by: the fallacious belief by workers needed to work to the maximum each day, and management promoting employee's own interests. To see how Taylor's approach is still used in developing countries, a study will be reported that was conducted on a large factory in the North-West of Iran. From this study we will illustrate the relationship between poor economic condition, human depreciation, and industrial organizations who use Taylor's Scientific Management approach
\end{abstract}

Keywords: Taylorism, Scientific management, Human depreciation, Productivity

\section{Introduction}

Recent industrial policies in the developed world have outsourced their work to various developing countries. Although such movement of industry can be valuable for the hosting countries (e.g., economic development [1]) there can also be negative effects, such as environmental degradation (e.g., [1]) and harsh working conditions [1]. Working conditions can also be harsh due to leaders within the industrial section at multiple levels (e.g., individual factory, one company, group of companies, state government) following the Classical approach to management. The Classical approach is a group of opinions on management of organizations from the late 19th and early 20th century. Due to the Industrial Revolution, leaders began looking for ways to increase productivity and efficiency. One of the theories developed to aid this is Scientific Management Theory [2], in which the time spent by employees on various tasks is rigorously analyzed. As a result of applying this theory, industry leaders can look for ways to optimize productivity in terms of the time spent on useful work. However, this may lead result in harm to employees as they reduce the time spent on necessary forms of recovery (e.g., breaks, proper nutrition, family time, etc.). To explore whether leaders are using Scientific Management Theory, and whether employees are behaving as though they were guided by this theory, an experiment was conducted to explore the relationship between how time was spent on the job and the resulting depreciation that occurs within employees and factory machinery. From this experiment it will become apparent that, at least in the area in which this experiment was conducted (Iran), there is an increasing emphasis on productive time that results in human depreciation (manifested as illness, injury, and lower productivity). The remainder of this paper will discuss: some of the background concepts behind Scientific Management Theory, the experiment methodology, the results of the experiment, and some conclusions and areas for future work.

\section{Literature Review}

A need for a better management approach came to pass directly due to classical contributors [3]. In the early period, management theories were not really outlooks but just some discrete practices or experiences. The classical approach of management first focused on rationality and constructing organizations and workforce as efficient as possible. This school of thought proposed a convenient framework for the education and training of future managers [4]. Up until the late 1950s, academic writing in organizational structure was dominated by the classical management school. This meant that there was just a single organizational structure, which was encouraged for all organizations [5]. The classical school is highly structured, with clearly defined functions and detailed workforces' rules, and an emphasis on the formal organization with autocratic leadership [6]. The three 
greatest proponents of classical theory were Taylor, Fayol, and Weber. Each identified detailed methods and principles through which this kind of organization could be achieved [7].

The classical approach to management was developed from 1900 to 1930, and it was the output of the first concentrated endeavor to improve a structure of management thought. However, people who wrote in this area and participated in this effort are considered the precursors of management science. This school of thought recommends that managers continually strive to enhance organizational efficiency for achieving high productivity; the classical approach is established on that doctrine [4]. The classical approach to management is divided into three different areas: Lower level management analysis or scientific management, Comprehensive analysis of management or administrative management, and Bureaucratic management. Each of these will be described below.

\subsection{Scientific Management Theory}

Scientific management prefers to find the "one best way" to perform a task, meaning that this method investigates productivity and to find a process of how a task situation can be structured to achieve the highest production from workers [4]. Scientific management was applied to all levels of management; however its studies, illustrations and research applications mostly focused on lower-level managers. In nearly all management papers Frederick W. Taylor (1856-1915) is called the father of scientific management. In 1875 he started his career in a small shop in Philadelphia (USA). Inefficiency was a popular property in his period [8]. In his research, Taylor focused on three important options: productivity, production efficiency, and making a mental revolution between labours and managers. Four principles of management were introduced by Taylor: 1 . Use the scientific method for elements of an individual's work instead of the old 'rule of thumb' method; 2. Workers must scientifically select and then train, teach, and develop their quality; 3. Workers must learn to work together and heartily cooperate with the others in order to ensure that all work is done; 4. Divide work and responsibility between management and workers [8]. Scientific management consists primarily of the work of Frederick W. Taylor, Frank and Lillian Gilbreth, and Henry L. Gantt. We will talk shortly in terms of Taylor's and Gilbreth's opinions because our research is related to their theories.

Frederick Taylor. Frederick Taylor was an American mechanical engineer who sought to improve industrial efficiency. He was one of the first management consultants, and has been called one of the intellectual leaders of the Efficiency Movement. His ideas, in a broad sense, were highly influential in the Progressive Era. Taylor summed up his efficiency techniques in his book The Principles of Scientific Management [9]. A summary of Taylor's beliefs includes: maximizing prosperity for owners, workers, and managers in industry; maximizing prosperity was possible by teaching workers and managers the most efficient way to do their work; workers and managers are mutually interdependent; and antagonism and inefficiency in the workplace was caused by: 1 . the fallacious belief by workers that unless they worked to the maximum each day they would lose their job; 2. defective management systems that caused workers to protect their own work and interests; 3. inefficient methods of work.

Frank and Lillian Gilbreth. After Taylor's Scientific Management Theory, Frank and Lillian Gilbreth suggested their Therbligs Approach. In this approach, 18 kinds of elemental motions are used to study the motion economy which workers must use in their workplace. A workplace task is analyzed by recording each of the therblig units for a process. The results can optimize manual labor by eliminating unneeded movements [10]. 


\begin{tabular}{|c|c|c|}
\hline$\infty$ & Search & U Use \\
\hline$\infty$ & Find & $\nexists$ Disassemble \\
\hline$\Rightarrow$ & Select & Inspect \\
\hline & Grasp & 8 Preposition \\
\hline & Hold & の Release Load \\
\hline & Transport Loaded & ○ Unavoidable Delay \\
\hline & Transport Empty & Avoidable Delay \\
\hline 9 & Position & 8 Plan \\
\hline \# & Assemble & ᄂ Rest \\
\hline
\end{tabular}

Fig. 1: A list of the 18 Therbligs (Source: [10]).

\subsection{Administrative Management}

In the second stage of Scientific Management Theory, the entire range of managerial performance is investigated; in other words, organizational efficiency is the area that Administrative Management likes to verify. Among the well-known participants in the comprehensive view are Fayol, Barnard, Brown, Dennision, Gulick and Urwick, Mooney and Reilly, and Sheldon [11]. Henri Fayol (1841 - 1925) was the most notable contributor, writing General and Industrial Management; this work presents a management philosophy that is still accepted by many modern managers. Fayol is usually considered the precursor in administrative theory because of the elements and general principles that his writings cover [4]. His elements of management include planning, organizing, commanding, coordinating and controlling and are still considered worthwhile divisions to study, affect, and analyze the management process. The principles developed by Fayol include: division of work, unity of command, authority, discipline, subordination of individual interest to general interests, unity of direction, remuneration, scalar chain, centralization, order, initiative, equity, and stability of tenure of personnel.

\subsection{Bureaucratic Management}

Bureaucratic management is a stream of classical management theory that is "a formal system of organization that is based on clearly defined hierarchical levels and roles in order to maintain efficiency, effectiveness, and accountability" [12]. Max Weber (1864-1924) developed this theory and management in both public and private sectors are able to utilize it in diverse organizations. According to the bureaucratic management approach, hierarchies are a similar character of these organizations. Within the organization, these divisions are able to create strong lines of authority and monitoring [13]. Additionally, Max Weber was the first management theorists who developed a theory in terms of authority structures and its relation with organizations. $\mathrm{He}$ argued for a form of organization determined by division of labour, detailed rules and regulations, clearly defined hierarchy, and impersonal relationships [14].

\section{Methodology}

In sociology, quantitative research focuses on the systematic empirical inquiry of social phenomena via statistical, numerical, or mathematical data or computational techniques [15]. The main objective of quantitative research is to create and improve mathematical models, hypotheses and/or theories pertaining to phenomena. Measurement is a necessary part of quantitative research, as it provides the necessary connection between observation and mathematical expressions. In the process of measurement quantitative data (e.g., statistics, percentages) are gathered through specific and narrow questions [15]. This data is then analyzed using statistical means, with the hope of obtaining an unbiased result that can be generalized to some larger population. 
This research studied human depreciation in a large factory in Iran. In this case, Iran is interpreted as a developing nation. Data was collected from 166 participants on a daily basis, along with annual summaries. The accuracy and confidence of the data collection was considered high. Workers have to use Taylor's Scientific Management Theory (SMT). In other words, if a worker is faster than the estimated time then he will be able to increase his income and the organization's productivity. In the data, some factors are defined as 'waste time' and this refers to a situation in which a worker or machine is not productive.

For collecting these numbers, we worked with three elements: Standard Times, Real Times, and Waste Times. Standard Time is the expected time required for production, while Real Time is the actual amount of time the production required. Waste Time is a category for events such as illnesses, days off, tardiness, and personal work. The goal of this research was to calculate useful time, which refers to time actually spent working, and to determine what events led to an increase or decrease in that value. Hence, useful time is the dependent variable while Waste Time and Job events (i.e., accidents) are independent variables.

In this discussion we would like to focus on three questions: Are Taylor's ideas used in any work atmosphere today? What are their strengths and weaknesses? When and how can we use this school of thought?

\section{Results}

In this section, we will present some results of this study. These results are presented as a correlation matrix, and some key relationships are identified and explained.

\subsection{Correlation Matrix}

A correlation matrix of $n$ variables is an $n$-by- $n$ matrix of values that show the correlation between those variables. This matrix is symmetric, since the correlation between $X_{i}$ and $X_{j}$ is the same as that between $X_{j}$ and $X_{i}$. The correlation values are between -1 to +1 , where negative values indicate a negative correlation (i.e., as one increases the other decreases) while positive values indicate a positive correlation (i.e., as one increases the other does as well). Below is a table showing some correlation coefficient values and their meaning.

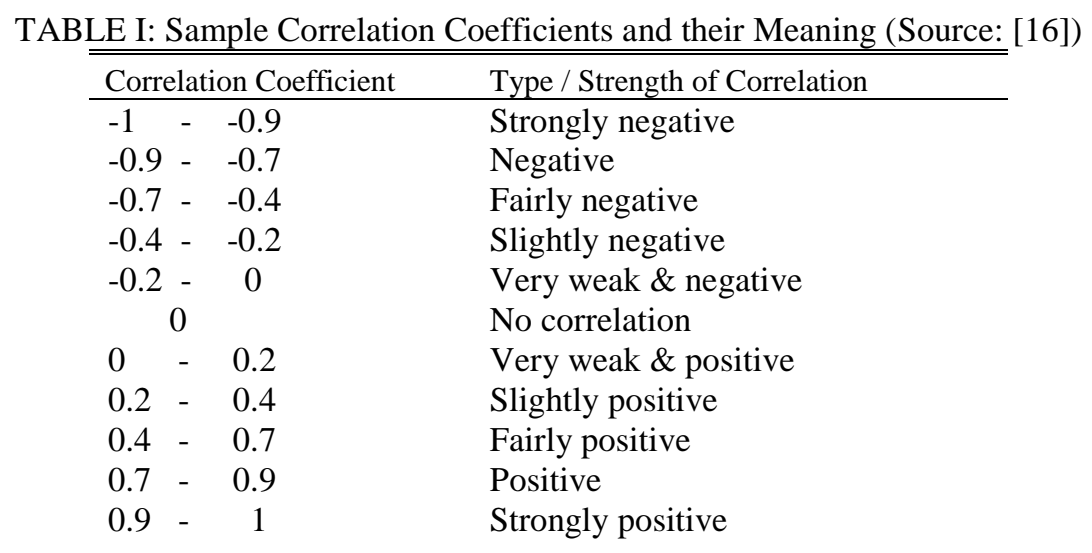

\subsection{Data Analysis}

The data was analyzed using SPSS, with the 'coefficient correlations matrix' between the independent and dependent variables shown in Table 2. 
International Conference on Studies in Humanities and Social Sciences (SHSS-2016) May 24-25, 2016 Paris (France)

TABLE II: Correlation Matrix for Useful Time vs. Wasted Time and Job Events.

\begin{tabular}{|c|c|c|c|c|c|c|c|c|c|c|c|c|}
\hline & UT & I & $\mathrm{D}$ & $\mathrm{T}$ & PW & E & $\mathrm{JE}$ & ET & I & A & WT & IP \\
\hline Useful time (UT) & 1 & 0.12 & -0.06 & -0.04 & $\begin{array}{c}-0.10 \\
\end{array}$ & 0.23 & -0.08 & 0.30 & 0.20 & 0.09 & -0.18 & 0.16 \\
\hline Illness (I) & & 1 & 0.29 & 0.12 & 0.53 & -0.33 & 0.01 & 0.41 & -0.14 & -0.02 & -0.11 & -0.14 \\
\hline Days off (D) & & & 1 & 0.09 & $0.19^{*}$ & -0.05 & 0.21 & -0.23 & 0.18 & -0.05 & -0.01 & 0.06 \\
\hline Tardiness $(\mathrm{T})$ & & & & 1 & $0.52 * *$ & -0.10 & $0.21 * *$ & -0.02 & 0.42 & 0.02 & 0.01 & -0.03 \\
\hline $\begin{array}{l}\text { Personal work } \\
\text { (PW) }\end{array}$ & & & & & 1 & $-0.31 * *$ & 0.06 & -0.15 & -0.02 & -0.28 & 0.07 & -0.04 \\
\hline Experience $(\mathrm{E})$ & & & & & & 1 & -0.05 & 0.07 & 0.09 & 0.85 & -0.09 & 0.08 \\
\hline Job event (JE) & & & & & & & 1 & -0.07 & 0.20 & -0.08 & 0.20 & -0.10 \\
\hline Extra Time (ET) & & & & & & & & 1 & -0.07 & 0.11 & -0.22 & -0.07 \\
\hline Instrument (I) & & & & & & & & & 1 & 0.20 & -0.07 & 0.26 \\
\hline Age (A) & & & & & & & & & & 1 & -0.09 & 0.12 \\
\hline Wasted time (WT) & & & & & & & & & & & 1 & -0.01 \\
\hline $\begin{array}{l}\text { Instrument Price } \\
\text { (IP) }\end{array}$ & & & & & & & & & & & & 1 \\
\hline
\end{tabular}

$* \mathrm{p}<0.05, * * \mathrm{p}<0.01$

A Positive Correlation between Illness and Extra Time (0.41). Illness refers to those times in which workers have to stay at home or a hospital by doctors' orders. Extra Time is when workers have produced something faster than the Standard Time. For example, a Standard Time for production in step "A" is 9 minutes while a worker is able to produce it in 7 minutes. Therefore, the factory is able to increase its capacity by this difference in time. Difference between Standard Time and Real Time is Extra Time. In developing countries, nearly all workers are not able to cover their cost of living so they have to find a second job or, in industrial factories, follow Taylor's Scientific Management Theory to achieve more Extra Time. Although it will improve the productivity of the factory it can also depreciate other factors like workers, machinery, instruments, and so on. This correlation (0.41) shows that Extra Time and Illness have a positive correlation. This means that as Extra Time increases there is also an increase in Illness.

A Positive Correlation between Tardiness and Job Event (0.21). This correlation shows that time of arrival is an important factor in this factory. When a worker arrives to his workplace late, for any reason, there is a greater possibility of job events (i.e., accidents).

A Positive Correlation between Tardiness and Instruments (0.42). This correlation illustrates that when a worker enters his workplace late, for any reason, to make up his Extra Time he will increase the speed of the machine(s). However, this leads to a higher depreciation of instruments.

A Negative Correlation between Days off and Extra Time (-0.23). This correlation illustrates that workers have a fundamental role in productivity; but with increased days off the factory is not able to achieve more productivity, because Extra Time is decreased. The correlation shows that the manufacturing system is not only machine-based but also labour-based.

A Negative Correlation between Personal-Work and Experience (-0.31) and a Negative Correlation between Personal-Work and Age (-0.28). Table 2 shows a positive correlation between Age and Experience, a negative correlation between Personal-Work and Experience, and a negative correlation between Personal-Work and age. This can be considered the same as "A negative correlation between Experience and Illness". However, experienced workers or older workers prefer to spend their time in workplace.

A Positive Correlation between Age and Instrument (0.20). As we explained before, one of main reasons that worker are able to work faster than Standard Time is the high speed of the machinery. It seems that more experienced workers depreciate the machinery and tools at a higher rate, possibly due to overuse of the machinery.

A Positive Correlation between Vacation Time and Instrument (0.20). Similarly, when people take more time off from work, there is increasing depreciation of machinery. This could be due to the employees using the machines at higher or harsher rates to make up for the time they lost on vacation. Alternatively, they could be using the machinery at a harder or harsher rate due to being more productive upon returning from vacation.

A Positive Correlation between Instrument and Price of Instrument (0.26). As the instruments are used more frequently, such that instrument depreciation increases, the cost on the instruments is likewise increased. 
Alternatively, this correlation could be that as the price of the instruments increase, they are used more frequently and thus depreciate faster.

\section{Discussion}

For developing our research we will discuss four topics in this section: appraisal of classical approach, organizational life cycle and management styles, and finally the weaknesses and strengths of Taylor's scientific management theory.

\subsection{Appraisal of Classical Approach}

Significant contributions to the improvement of management theories were made by the classical approach. These contributions included three important issues: focus on labours' productivity within organizations, search methods to improve their efficiency, and eliminating managerial inconsistencies [17]. In other words, the classical approach confirmed the position that a person and organization continues even when employees leave the organization, and distinguished the universal character of management principles [18]. In addition, the classical approach made a clear distinction between the activities of managers and those of workers. It also showed that the scientific method can be applied to management problems, and indicated that mutual cooperation between employees and their employers is needed.

Some criticisms have been levelled against the classical approach. First, the theories within it are said to be too formal, making them difficult for many people to use properly. Second, the approach is said to be more appropriate for stable and simple organizations, yet today's organizations are very complex and dynamic. Hence, the classical approach may not be applicable to any modern or newer organizations. Third, the prescriptions from the classical approach are universal in application. Often, this means the prescriptions are not specific or relevant enough in particular contexts for them to be practically useful.

\subsection{Organization Life Cycle and Management Style}

Since the classical approach is seen as being not applicable to newer organizations, it would be useful to look at organizations and the relationship with management and their duties. An organization is a systematic arrangement of people to accomplish some specific purpose. Every organization is composed of three elements: goals, people, and systems. Each organization has a distinct purpose, and this purpose is generally expressed as goals. A systematic structure in all organizations is able to define the limit of each member. These organizations can also be seen as being alive, and so they pass through some stages: birth, early growth, growth maturity, decline, and recovery [19].

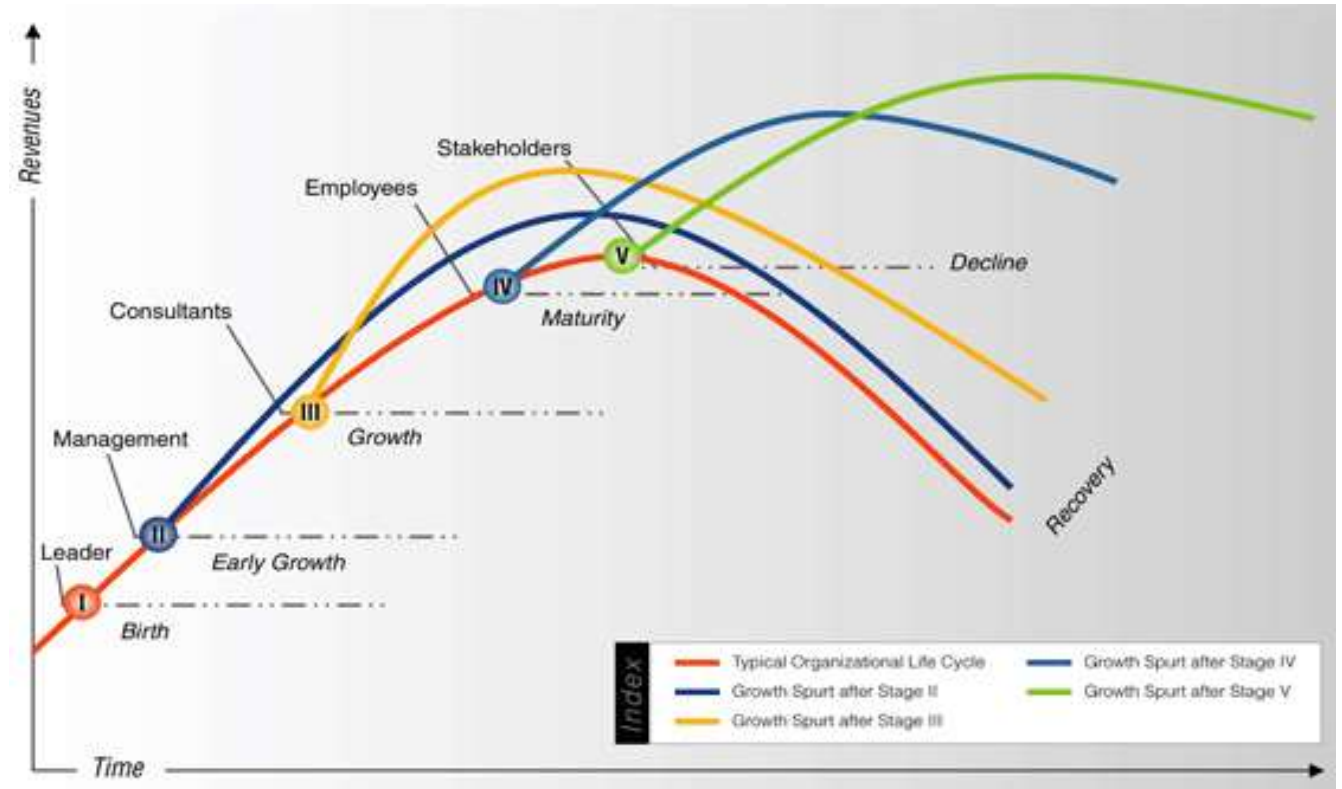

Fig. 2: Organizational life cycle (OLC) (Source: [19]) 
However, the way in which leaders should act and make decisions depends on the stage of the organization. Five such stages can be identified: leader, management team, consultants, employees, and stakeholder [20].

Stage I: Leader. Leadership in this stage uses a top-down approach, which means that the head of the organization makes all decisions and these are then implemented by the employees. There is likely to be no visibility into the ideas by the rest of the organization. This stage is suggested for small organizations and startups where quick decisions are required.

Stage II: Management Team. In this stage the management team makes decisions. This team represents a small percentage of the entire organization. Strategic issues are discussed by this team and decisions are made by consensus. Again, the decisions are implemented by the employees using a top-down model. Ideas are not visible for all and they are localized within immediate sub-units. In other words, each member of the management team can share with or discover the ideas of his/her immediate subordinates. Organizations which are in their early growth phase can use this stage, but the system must still be a small one.

Stage III: Consultants. For this stage, final decisions are made by the management team but it engages in consultation with experts in their field. These experts could be either external or internal to the organization. Suggested ideas require some level of validation for their relevance to the targets of the organization. Organizations that are in their growth phase can follow this stage, during which the organization would require a new or better perspective to achieve a paradigm shift.

Stage IV: Employees. In this stage, the role of employees is further understood. Decision making requires input from all employees. These opinions (input) are filtered, validated, and then used to make a final decision. Although the management team makes the final decision, they can gather ideas from within the entire organization through a process that receives and nurtures employee input. This stage is best suited for large organizations that are mature and enforce the need for a paradigm shift.

Stage V: Stakeholders. This stage is very democratic, where input is requested not only from employees but also from other strategic stakeholders. These groups are able to contribute to the growth and decision making of all levels of the organization. Filtering and validating ideas are the responsibility of individuals. For organizations that are mature global organizations with stable processes, they must be able to use high capacity processes to channel ideas from such a large population.

As a company progresses from one stage to another, the reach of the idea-management system increases. More people are involved in the decision-making process. As the number of ideas to scan and filter increases, the need for proper processes in place also increases. Thus, the robustness of the process needs to increase from one stage to another.

TABLE III: Different policies based on Organizational Life Cycle (Source: [19])

\begin{tabular}{|c|c|c|c|c|c|}
\hline Stage & $\begin{array}{l}\text { I } \\
\text { Leader }\end{array}$ & $\begin{array}{l}\text { II } \\
\text { Management } \\
\text { Team }\end{array}$ & $\begin{array}{l}\text { III } \\
\text { Consultants }\end{array}$ & $\begin{array}{l}\text { IV } \\
\text { Employees }\end{array}$ & $\begin{array}{l}\text { V } \\
\text { Stakeholders }\end{array}$ \\
\hline Who & One Person & $\begin{array}{l}\text { Small } \\
\text { Percentage }\end{array}$ & $\begin{array}{l}\text { Small \% with } \\
\text { Consultants }\end{array}$ & Entire employee base & All strategic stakeholders \\
\hline How & Leader's ideas & $\begin{array}{l}\text { Team's } \\
\text { consensus in } \\
\text { silo }\end{array}$ & $\begin{array}{l}\text { Consultants } \\
\text { expertise relied upon }\end{array}$ & $\begin{array}{l}\text { Suggestions and ideas } \\
\text { from within the company }\end{array}$ & $\begin{array}{l}\text { Suggestions and ideas } \\
\text { from one and all }\end{array}$ \\
\hline Process & None required & $\begin{array}{l}\text { Required only } \\
\text { for approval }\end{array}$ & $\begin{array}{l}\text { Required for } \\
\text { validation }\end{array}$ & $\begin{array}{l}\text { Robust process required } \\
\text { for collecting, filtering } \\
\text { and validating }\end{array}$ & $\begin{array}{l}\text { Robust process required } \\
\text { for collecting, filtering, } \\
\text { aligning and validating }\end{array}$ \\
\hline Steps & $\begin{array}{l}\text { Decide - } \\
\text { Implement }\end{array}$ & $\begin{array}{l}\text { Discuss - } \\
\text { Approve - } \\
\text { Implement }\end{array}$ & $\begin{array}{l}\text { Suggest - Validate - } \\
\text { Approve - } \\
\text { Implement }\end{array}$ & $\begin{array}{l}\text { Collect ideas - Filter - } \\
\text { Validate - Approve - } \\
\text { Implement }\end{array}$ & $\begin{array}{l}\text { Collect ideas - Filter - } \\
\text { Align - Validate - } \\
\text { Approve - Implement }\end{array}$ \\
\hline Responsibility & Leader & $\begin{array}{l}\text { Team, } \\
\text { collectively }\end{array}$ & Team, collectively & $\begin{array}{l}\text { Program Management } \\
\text { Office }\end{array}$ & $\begin{array}{l}\text { Program Management } \\
\text { Office }\end{array}$ \\
\hline Dependency & Person-dependent & $\begin{array}{l}\text { Team- } \\
\text { dependent }\end{array}$ & Team-dependent & Process-dependent & Process-dependent \\
\hline Effort & Not Conscious & Not Conscious & Partially Conscious & Conscious \& Focused & Conscious \& Focused \\
\hline Time to Decision & Fastest & Fast & Medium & Slow & Slowest \\
\hline
\end{tabular}

\subsection{Weaknesses and Strengths of Taylor's model}

According to [21], provide some strengths and weakness of Taylor's model, as summarized below. Some strengths include: 
1. Formal separation between managers and workers

2. More efficient production methods from both managers and workers results in a significant global increase in standard of living

3. Focused on the tasks and actual work rather than processes

4. Emphasized direct reward mechanisms for workers

5. Systematic improvement of quality standards

6. Incorporates worker suggestion and cash rewards for involvement

7. Emphasized measurement, more easily identifying areas of improvement

In contrast, some weaknesses include:

1. Easily enables human exploitation and conflict with labor unions

2. Not useful for analyzing groups or organizational initiatives

3. Individual preferences are ignored

4. Too much measuring can lead to less-easily measurable factors being ignored

5. Treats humans as machines

6. Separation between the planning and doing stages of work

7. Worker skill and autonomy ignored; less useful for knowledge environments

One of the biggest problems with using Taylor's scientific management theory, especially in developing countries, is human depreciation. Nearly all of the workers in this study were not able to support their life with a regular monthly income. This factory also emphasized increasing its productivity, due to market control through government policy. As explained in the analysis, workers will be able to achieve more income if they work faster than the Standard Time. Gilbreths' Therbligs method was suggested to protect workers, but the workers in this particular company do not follow these regulations. For example, in the standard definition a worker has to take, move, and put materials which are heavier than $10 \mathrm{KG}$ on machine by crane. However, when the crane is busy workers prefer to do these actions by hand to save Standard Time; though problems such as arthritis and work accidents can result (see positive correlation between Illness and Extra time). Additionally, Extra Time can be treated as an income. Tardiness or days off mean lower Extra Time, or lower income (see negative correlation between Days off and Extra Time). Therefore, experienced workers use various means to compensate, such as increasing the operating speed of machinery. This is a fundamental reason to for instrument depreciation and job events (see positive correlation between Tardiness and Instruments; positive correlation between Tardiness and Job event). The high speed of machines is also a reason for accidents and is prevalent among experienced workers (see negative correlation between Experience and Illness; positive correlation between Age and Instrument; and positive correlation between Job-Event and Instrument).

If these workers are not able to work for a long time then they have to leave their job. This suggests two fundamental problems for the factory in particular and the wider society. For the factory, the organization will lose workers who have high degrees of expertise, skill, knowledge, and education. Additionally, the factory will have to hire new workers, spend a lot of money to train them, and the efficiency of these workers will definitely be lower. For society, the workers now end up relying on government support (such as National Health Services or disability services), and these workers will not be able to support their family. Combined with cultural emphasis on working, when parents (almost always the father) are not able to work the children (again, usually male children) are strongly pressed to leave school and work. A high dropout rate has irreversible effects on the community. Hence, there are significant societal costs for a worker leaving a job due to injury, exhaustion, or simply inability to continue working.

\section{Conclusion}

The goal of this paper is to answer three important questions related to Taylor's Scientific Management Theory: Are Taylor's ideas used in any work atmosphere today? What are their strengths and weaknesses? When and how can we use this school of thought? To answer the first question, this research shows that Taylor's theory is currently being used. After developing a global approach, some owners of capital prefer to transfer their industrial factories to developing countries because cheaper labours can bring more profit. This movement changed the job market, but many developing countries preferred to use the Taylor's theory for increasing productivity. 
The second question was answered in section 5.3, where we discussed some of the strengths and weaknesses in relation to our research. For example, using Taylor's theory with Standard Time can lead to problems in worker and machine depreciation, and Extra Time is a profitable variable but can lead to long term problems in the factory and wider society. Despite its benefits, it is likely better to use other theories. To limit accidents in these kinds of factories, leaders should work with psychologists to support workers when they arrive late. It is better for them to not be late at all or, if they are late, to not work harder to make up for it. If companies have to use Taylor's theory, workers on the shop floor should be protected with new instruments. A major employee policy can be to monitor new workers and pursue a financial support system for them, to ensure they do not try to push themselves too hard. Job training systems will be necessary for more experienced worker. However, we believe the biggest weakness of the scientific management theory is human depreciation, which has a negative effect on the company and society.

For the third question we need to look at the Organizational Life Cycle (OLC). In the second stage and the first years of third stage (Early Growth and Growth) it can be useful to follow Taylor's theory. In other stages though, different approaches are more appropriate. As we explained in Section 5.2, the second stage is where the management team makes decisions in a top down manner. This team represents a small percentage of the entire organization, but they discuss and decide upon strategic issues. Ideas are not visible for all and they are localized within immediate sub-units. In this early growth period, markets tend to become more inundated with companies, competition increases drastically, alliances and joint ventures are formed, and advertising and brand building become more dominant. In such a state, Taylor's theory can give companies an edge. However, as markets stabilize and the company must optimize itself for long-term dominance, the disadvantages of Taylor's theory will take higher precedence and should be abandoned.

\section{References}

[1] J. M. Martinez, American Environmentalism: Philosophy, History, and Public Policy. CRC Press, 2013. http://dx.doi.org/10.1201/b15063

[2] M. Witzel, A history of management thought. New York: Routledge, 2012.

[3] R. K. Sapru, Administrative theories and management thought. PHI Learning Pvt. Ltd., 2013.

[4] S. Certo and S. T. Certo, Modern Management, $10^{\text {th }}$ ed. 2006.

[5] R. E. Miles, Theories of management: Implications for organizational behavior and development. New York, NY: McGraw-Hill, 1975.

[6] K. Bartol, M. Tein, G. Matthews, and D. Martin, Management: A Pacific Rim Focus, enhanced ed. 2003.

[7] P. Hersey, K. H. Blanchard, and D.E. Johnson, Management of Organizational Behavior. 1988.

[8] S. Robbins, R. Bergman, I. D. Stagg, and M. Coulter, Foundations of Management. 2002.

[9] D. Nelson, Frederick W. Taylor and the rise of scientific management. Madison, WI: University of Wisconsin Press, 1980.

[10] M. C. Wood and J. C. Wood (Eds.), Frank and Lillian Gilbreth: Critical Evaluations in Business and Management, vol. 2. Taylor \& Francis, 2003.

[11] J. T. Heames and J. W. Breland, "Management pioneer contributors: 30-year review," Journal of Management History, vol. 16, no. 4, pp. 427-436, 2010. http://dx.doi.org/10.1108/17511341011073915

[12] J. Forrer, J. J. Kee, and E. Boyer, Governing Cross-Sector Collaboration. New York, NY: John Wiley \& Sons, 2014.

[13] J. R. Schermerhorn, J. G. Hunt, and R. N. Osborn, Managing organizational behavior. New York, NY: Wiley, 1991.

[14] D. A. Wren, The Evolution of Management Thought, 4th ed. New York, NY: Wiley, 1994.

[15] L. M. Given (Ed.), The Sage encyclopedia of qualitative research methods. New York, NY: Sage Publications, 2008. http://dx.doi.org/10.4135/9781412963909

[16] S. Puntanen, "Matrix Algebra. Theory, Computations, and Applications in Statistics by James E. Gentle," International Statistical Review, vol. 75, no. 3, pp. 435-435, 2007. http://dx.doi.org/10.1111/j.1751-5823.2007.00030_28.x

[17] L. L. Martin, Total quality management in human service organizations, Vol. 67. New York, NY: Sage Publications, 1993. http://dx.doi.org/10.4135/9781483326597

[18] V. Berdayes, "Traditional management theory as panoptic discourse: language and the constitution of somatic flows," Culture and Organization, vol. 8, no. 1, pp. 35-49, 2002.

http://dx.doi.org/10.1080/14759550212102

[19] J. McAuley, J. Duberley, and P. Johnson, Organization theory: Challenges and perspectives. Pearson Education, 2007. 
[20] A. Goyal and S. Kousalya (2007), "Institutionalizing innovation: Look to employees for the next great idea," Ivey business journal. Available: http://iveybusinessjournal.com/topics/the-organization/institutionalizing-innovation-lookto-employees-for-the-next-great-idea\#.VBisC_BX-uY

[21] H. G. Aitken and M. R. Smith, Scientific management in action: Taylorism at Watertown Arsenal, 1908-1915, p. 135. Princeton: Princeton University Press, 1985. http://dx.doi.org/10.1515/9781400857890 